REVIEW ARTICLE

\title{
Sinonasal Verrucous Carcinoma
}

Sajad M Qazi, Irfan Iqbal, Aneesa Mirza, Ihshan Ali, Sheetal

\section{ABSTRACT}

Verrucous carcinoma is a low-grade malignancy and is a variant of squamous cell carcinoma. It is a rare tumor of the sinonasal tract. The neoplasm occurs in older people usually in the seventh or eighth decade of life. Our cases were both of sinonasal origin and of younger age group.

Keywords: Chemoradiotherapy, Sinonasal postoperative.

How to cite this article: Qazi SM, Iqbal I, Mirza A, Ali I, Sheetal. Sinonasal Verrucous Carcinoma. Int J Head and Neck Surg 2012;3(3):163-164.

Source of support: Nil

Conflict of interest: None declared

\section{INTRODUCTION}

Verrucous carcinoma is a rare entity in the sinonasal tract. ${ }^{1}$ It was first described and characterized as a distinct entity in 1948 by Ackerman. ${ }^{2}$ Verrucous carcinoma involving the upper aerodigestive tract is most in the oral cavity with the glottic larynx being the most frequent non-oral head and neck site. ${ }^{3}$ Verrucous carcinoma of the nose has been reported to involve the columella, ${ }^{4}$ nasal septum, ${ }^{5}$ nasopharyn $x^{6}$ and uncommonly the paranasal sinuses. The incidence varies from 4.5 to $9 \%$ and elderly men are most often affected. ${ }^{7}$

\section{DISCUSSION}

Verrucous carcinoma is a highly differentiated variant of squamous cell carcinoma. ${ }^{8}$ It has cytological and architectural features similar to that of a reactive process and not that of invasive carcinoma. However, it has the ability to invade normal tissues to a limited extent, demonstrating its aggressiveness. ${ }^{9}$ The gross appearance is usually a warty, gray white lesion with filiform projections. The characteristic histologic features are highly keratinizing surface, papillary areas and apparent absence of dysplastic changes in the squamous epithelium. ${ }^{8}$ Regional lymph node metastasis and distant metastasis are extremely rare. ${ }^{5}$ Tobacco plays a significant role in the pathogenesis of verrucous carcinoma of the aerodigestive tract. ${ }^{2}$ An association between human papilloma virus and verrucous carcinoma has also been proposed. However, results have been inconsistent. Although HPV types 6, 11, 16 and 18 have been detected to varying degrees in verrucous carcinoma of the oral cavity and the larynx. ${ }^{10,11}$ Orvidas et al could detect no HPV in association with nasal and paranasal sinus verrucous carcinoma using the polymerase chain reaction technique. ${ }^{12}$

The main histopathological differential diagnosis of verrucous carcinoma is from leukoplakia, papilloma, pseudoepitheliomatous hyperplasia, verrucous hyperplasia and highly differentiated squamous cell carcinoma. ${ }^{13}$

Treatment of verrucous carcinoma remains controversial. Surgery is the mainstay of treatment of this neoplasm. Radiotherapy is reported to cause anaplastic change in the tumor within 6 months, making it more aggressive with change of distant metastasis. ${ }^{14,15}$

\section{CASE REPORTS}

\section{Case 1}

A 30-year-old female, housewife by occupation, presented to our hospital with left nasal obstruction and left nasal anosmia for 1 year. The patient's medical history was unremarkable. Anterior rhinoscopy revealed a grayish white mass which was insensitive to touch in left nasal cavity. Routine laboratory tests were within normal limits. Contrast enhanced CT PNS revealed (Fig. 1). Preoperative biopsy of the nasal mass was suggestive of verrucous squamous neoplasm. Left subtotal maxillectomy, left anterior and posterior ethmoidectomy, left sphenoidotomy, left frontal sinusotomy with orbital floor repair was done. The patient had an uneventful postoperative recovery. Histopathological examination of the surgical specimen showed marked hyperplasia of epidermis with thick bands of parakeratin, bland squamous cells with broad rete ridges suggesting diagnosis of verrucous carcinoma.
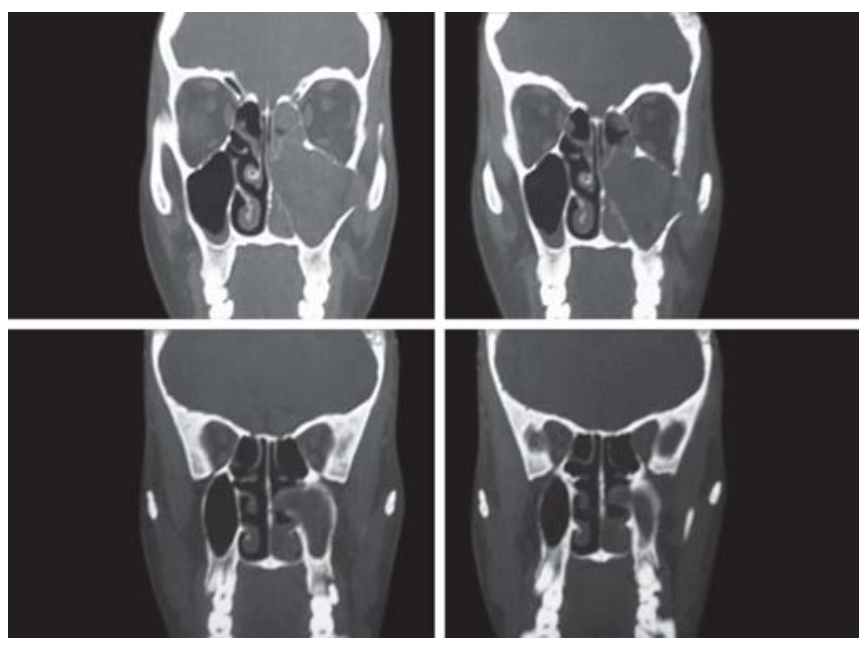

Fig. 1: Contrast enhanced mass involving whole of left nasal cavity going into inferior margins of orbit 


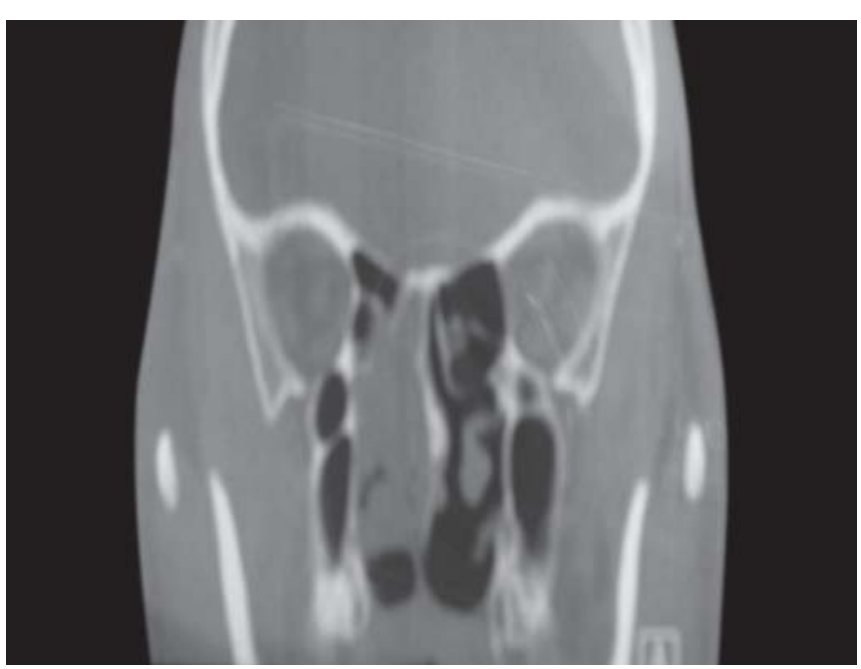

Fig. 2: Contrast enhanced mass involving right nasal cavity involving both anterior and posterior ethmoids

\section{Case 2}

A 50-year-old male presented with complaints of right nasal obstruction for last 5 months. The patient was operated 2 years back for same complaint by endoscopic approach. Histopathological examination of the resected specimen showed squamous papilloma. Presently on anterior rhinoscopy, no mass was visualized and contrast enhanced CT PNS showed (Fig. 2). Endoscopic excision of mass was planned. Intraoperatively mass was seen involving right maxilla, anterior and posterior ethmoids, sphenoid and roof of nasal cavity. Postoperative period was uneventful. Postoperative histopathological examination of specimen was compatible with verrucous carcinoma.

\section{REFERENCES}

1. Michaels L. Ear nose and throat histopathology. London: Springer-Verlag 1987:171-73.

2. Ackerman LV. Verrucous carcinoma of the oral cavity. Surgery 1948;23:670-78.

3. Taybos GM, Feltman R, Terezhalmy GT. Verrucous carcinoma invading the orbit. Report of a case. J oral Med 1983;38:31-34.

4. Vico P, Nagypal P, Rahier I, Derraemaecker R. Verrucous carcinoma of the nasal septum and columella. Acta Chir Belg 1997;97:50-51.

5. Hanna GS, Ali MH. Verrucous carcinoma of the nasal septum. J Laryngol Otol 1987;101:184-87.

6. Wolff AP, Ossoff RH, Clemis JD. Four unusual neoplasms of the nasopharynx. Otolaryngol Head Neck Surg 1980;88:753-59.
7. Spiro RH. Verrucous carcinoma, then and now. Am J Surg 1998;176:393-97.

8. Michaels L. Ear nose and throat histopathology. London: Springer-Verlag 1987:409-15.

9. Sternberg SS. Diagnostic surgical pathology. Philadelphia: Lipincott Raven Publishers 1996:906-08.

10. Fliss DM, Noble-Topham SE, McLachlin CM, et al. Laryngeal verrucous carcinoma. A clinicopathologic study and detection of human papilloma virus using polymerase chain reaction. Laryngoscope 1994;104:146-52.

11. Shroyer KR, Greer RO, Fankhouser CA, et al. Detection of human papilloma virus DNA in oral verrucous carcinoma by polymerase chain reaction. Mod Pathol 1993;6:669-72.

12. Orvidas LJ, Lewis JE, Olsen KD, Weiner JS. Intranasal verrucous carcinoma: Relationship to inverting papilloma and human papilloma virus. Laryngoscope 1999;109:371- 75.

13. Schrader M, Laberke HG. Differential diagnosis of verrucous carcinoma in the oral cavity and larynx. J Laryngol Otol 1988;102:700-03.

14. Fonts EA, Greenlaw RH, Rush BJ, Roven S. Verrucous squamous cell carcinoma of the oral cavity. Cancer 1969;23:152-60.

15. Biller HF, Bergmann JA. Verrucous carcinoma of the larynx. Laryngoscope 1975;85:1698-700.

\section{ABOUT THE AUTHORS}

\section{Sajad M Qazi}

Associate Professor, Department of Otorhinolaryngology and Head and Neck Surgery, SMHS Hospital, GMC Srinagar, Jammu and Kashmir, India

\section{Irfan Iqbal (Corresponding Author)}

Registrar, Department of Otorhinolaryngology and Head and Neck Surgery, SMHS Hospital, GMC Srinagar, Jammu and Kashmir, India e-mail: irfaniqbal0809@yahoo.com

\section{Aneesa Mirza}

Postgraduate Scholar, Department of Otorhinolaryngology and Head and Neck Surgery, SMHS Hospital, GMC Srinagar, Jammu and Kashmir India

\section{Ihshan Ali}

Lecturer, Department of Otorhinolaryngology and Head and Neck Surgery, SMHS Hospital, GMC Srinagar, Jammu and Kashmir, India

\section{Sheetal}

Postgraduate Student, Department of Otorhinolaryngology and Head and Neck Surgery, SMHS Hospital, GMC Srinagar, Jammu and Kashmir, India 